\title{
Efficacy of Bailing Capsule (Traditional Chinese Medicine) in the Treatment of Nephrotic Syndrome: A Meta-analysis
}

\author{
A. CHENG, YIJU LI ${ }^{*}$, S. LI2* AND Lan Wang ${ }^{3}$ \\ Department of Purchasing, Liaocheng Second People's Hospital, Shandong, PR China 650032, 1Department of Pharmacy, \\ Liaocheng Second People's Hospital, Shandong, PR China 650032, 2Department of Imaging, Jinan Central Hospital, \\ Shandong, PR China 650500, 3Department of Gastroenterology,Medical Institute of Guizhou Medical University, Guizhou, \\ PR China 550000
}

\section{Cheng et al.: Eficacy of Bailing Capsule in the Treatment of Nephrotic Syndrome}

\begin{abstract}
Meta-analysis of the existing literature on the treatment of nephrotic syndrome with Bailing capsule in adult patients was carried out to provide evidences for clinical practice. Relevant articles describing the effect were included. A total of 5 documents were selected. The meta-analysis showed that Bailing capsule reduced $24 \mathrm{~h}$ urine protein in patients with nephrotic syndrome (standardized mean difference=2.35 $(3.72,0.97)$, p<0.01), increased the level of serum albumin (standardized mean difference $=0.94(0.37,1.52), p=0.01)$, but had no improvement on serum creatinine (standardized mean difference $=0.50(1.25,0.26), p=0.20)$ as well as blood urea nitrogen (standardized mean difference $=0.10 \quad(0.36,0.17), p=0.48)$. The adjuvant treatment of nephrotic syndrome with Bailing capsule could reduce proteinuria, enhance plasma albumin and decrease blood lipids in patients. However, these conclusions need to be confirmed by further clinical trials.
\end{abstract}

Key words: Bailing capsule, nephrotic syndrome, proteinuria, urea nitrogen, meta-analysis

Clinical nephrotic syndrome (NS) is manifested as proteinuria, hypoalbuminemia and hyperlipidemia, which, in the long run, will promote glomerular sclerosis during the progress of NS and gradually develop into end-stage renal failure ${ }_{[1]}$. In traditional Chinese medicine (TCM), NS belongs to the category of edema and essence and vital energy collapse. The disease is characterized by edema and TCM postulates that the pathological mechanism is mainly spleen and kidney dysfunction, deficiency of as well as $q i$ and blood, especially the deficiency of yang qi is Ben and water-dampness, damp and hot as well as stagnation of blood stasis is Biao, represented as both of deficiency and excess; and it is susceptible to exogenous evils during the course of the disease and the condition is likely to be aggravated due to infections caused by exogenous pathogenic factors[2,3]. The pathogenesis of NS is complicated, closely related to lung, spleen and kidney. At present western medicine mainly uses glucocorticoids treatment and cytotoxic drugs, which pose many problems such as recurrence, hormone dependence and toxic side effects despite

${ }^{*}$ Address for correspondence 

density lipoprotein (LDL) and one report showed that Bailing capsule can increase the level of high density lipoprotein (HDL, Tables 2-5).

$\mathrm{Q}$ heterogeneity test and $I_{2}$ test showed that except the effect size index of blood urea nitrogen $(\mathrm{p}=0.86$, $\mathrm{I}_{2}=0 \%$ ), there was significant heterogeneity in the combination of other indicators. The funnel plot indicated a possibility of publication bias, as shown in fig. 2.

In summary a total of 5 documents were included in the meta-analysis, which showed that Bailing capsule reduced $24 \mathrm{~h}$ protein urine in patients with NS, increased the level of serum albumin, did not cause any improvement in serum creatinine and blood urea nitrogen levels. However, 2 of the selected articles reported that Nailing capsules can reduce total blood cholesterol, triglycerides and LDL. These results suggested that the adjuvant treatment of NS with Bailing capsule can further reduce proteinuria, enhance plasma albumin and decrease blood lipids in patients, all of which, however, need to be confirmed by further clinical trials.

NS results from a variety of causes. If a large amount of urine protein is lost from the body, the content of plasma albumin would be reduced and then it will lead to the decrease of blood volume. The excretion of some fibrinogen or anticoagulant factors increases the viscosity of blood, giving rise to the disorders of

TABLE 2: EFFECT OF THE BAILING CAPSULE ON THE URINE PROTEIN IN PATIENTS

\begin{tabular}{lcccccccc}
\hline & \multicolumn{3}{c}{ Bailing capsule group } & \multicolumn{3}{c}{ Bailing capsule group } & \multicolumn{2}{c}{ Std. Mean difference } \\
\hline $\begin{array}{l}\text { Study or } \\
\text { subgroup }\end{array}$ & Mean & SD & Total & Mean & SD & Total & Weight & IV, Random, 95 \% Cl \\
\hline Ying Liu & 0.97 & 0.08 & 34 & 3.45 & 0.29 & 34 & $14.70 \%$ & $-11.53[-13.58,-9.47]$ \\
Sha Li & 0.9 & 0.42 & 42 & 0.91 & 0.041 & 40 & $21.40 \%$ & $-0.03[0.47,0.41]$ \\
Wenqi Zhong & 3.1 & 0.97 & 20 & 3.83 & 1.33 & 66 & $21.20 \%$ & $-0.58[-1.08,0.07]$ \\
Cheng Chen & 1.21 & 0.32 & 45 & 2.11 & 0.69 & 40 & $21.20 \%$ & $-1.69[-2.19,-1.19]$ \\
Hongmi Cao & 1.67 & 1.42 & 48 & 2.53 & 0.73 & 48 & $21.40 \%$ & $-0.76[-1.16,-0.35]$ \\
Total (95\% Cl) & & & 189 & & & 228 & $100.00 \%$ & $-2.35[-3.72,0.97]$ \\
\hline
\end{tabular}

Heterogeneity: $\mathrm{Tau}_{2}=2.26 ; \mathrm{Chi}_{2}=129.61 ; \mathrm{df}=4(<0.00001) ; \mathrm{I}_{2}=97 \%$, test for overall effect: $\mathrm{Z}=3.34(\mathrm{p}=0.0008)$

\section{TABLE 3: ANALYSIS OF THE EFFECT OF BAILING CAPSULE ON SERUM CREATININE}

\begin{tabular}{lcccccccc}
\hline & \multicolumn{3}{c}{ Bailing capsule group } & \multicolumn{3}{c}{ Control group } & \multicolumn{2}{c}{ Std. mean difference } \\
\hline Study or subgroup & Mean & SD & Total & Mean & SD & Total & Weight & IV, Random, 95 \% Cl \\
\hline Ying Liu & 34.16 & 5.47 & 34 & 29.48 & 3.58 & 34 & $32.60 \%$ & $1.00[0.49,1.51]$ \\
Wenqi Zhong & 33.66 & 10.86 & 20 & 30.28 & 7.45 & 66 & $32.60 \%$ & $0.40[-0.10,091]$ \\
Hongmin Cao & 35.72 & 3.21 & 50 & 28.51 & 6.51 & 50 & 34.8 & $1.39[0.96,1.83]$ \\
Total (95\% Cl) & & & 104 & & & 150 & $100.00 \%$ & $0.94[0.37,1.52]$ \\
\hline
\end{tabular}

Heterogeneity: $\mathrm{Tau}_{2}=0.20 ; \mathrm{Chi}_{2}=8.49 ; \mathrm{df}=2(=0.01) ; \mathrm{I}_{2}=76 \%$, test for overall effect: $\mathrm{Z}=3.22(p=0.001)$

TABLE 4: ANALYSIS OF THE EFFECT OF BAILING CAPSULE ON SERUM CREATININE

\begin{tabular}{lcccccccc}
\hline & \multicolumn{3}{c}{ Bailing capsule group } & \multicolumn{3}{c}{ Control group } & \multicolumn{2}{c}{ Std. mean difference } \\
\hline Study or subgroup & Mean & SD & Total & Mean & SD & Total & Weight & IV, Random, 95 \% Cl \\
\hline Ying Liu & 125.88 & 11.06 & 34 & 126.59 & 13.24 & 34 & $25.00 \%$ & $-0.06[-0.53,0.42]$ \\
Wenqi Zhong & 43.48 & 11.75 & 20 & 71.5 & 15.56 & 66 & $23.80 \%$ & $-1.88[-2.46,-1.30]$ \\
Cheng Chen & 90.53 & 20.01 & 45 & 90.11 & 19.87 & 40 & $25.40 \%$ & $0.02[-0.41,0.45]$ \\
Sha Li & 88.67 & 18.58 & 42 & 91.44 & 15.75 & 40 & $25.80 \%$ & $-0.16[-0.55,0.23]$ \\
Total $(95 \% \mathrm{Cl})$ & & & 141 & & & 180 & $100 \%$ & $-0.50[-1.25,0.26]$ \\
\hline
\end{tabular}

Heterogeneity: $\mathrm{Tau}_{2}=0.53 ; \mathrm{Chi}_{2}=32.22 ; \mathrm{df}=3(<0.00001) ; \mathrm{I}_{2}=91 \%$, test for overall effect: $\mathrm{Z}=1.29(\mathrm{p}=0.20)$

TABLE 5: ANALYSIS OF THE BAILING CAPSULE AFFECTING BLOOD UREA NITROGEN

\begin{tabular}{lcccccccc}
\hline & \multicolumn{3}{c}{ Bailing capsule group } & \multicolumn{3}{c}{ Control group } & Std. mean difference \\
\hline Study or subgroup & Mean & SD & Total & Mean & SD & Total & Weight & IV, Random, 95 \% Cl \\
\hline Ying Liu & 125.88 & 11.06 & 34 & 129.26 & 23.15 & 34 & $31.7 \%$ & $-0.18[-0.06,0.29]$ \\
Wenqi Zhong & 6.1 & 1.2 & 20 & 6.25 & 1.31 & 66 & $28.7 \%$ & $-0.12[-0.62,0.38]$ \\
Cheng Chen & 5.83 & 1.8 & 45 & 5.85 & 1.72 & 40 & $39.6 \%$ & $-0.01[-0.44,0.41]$ \\
Total (95\% C) & & & 99 & & & 140 & $100.0 \%$ & $-0.10[-0.36,0.17]$ \\
\hline
\end{tabular}

Heterogeneity: $\mathrm{Tau}_{2}=0.00 ; \mathrm{Chi}_{2}=0.29 ; \mathrm{df}=2(=0.86) ; \mathrm{I}_{2}=0 \%$, test for overall effect: $\mathrm{Z}=0.70(p=0.48)$ 


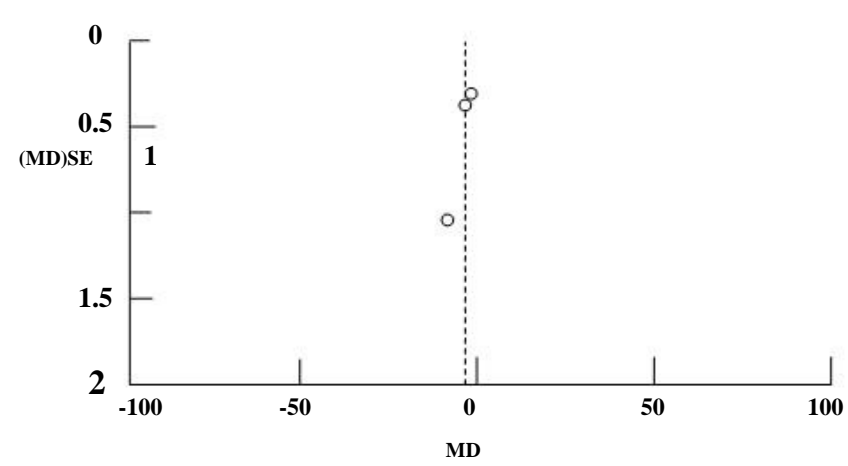

Fig. 2: Funnel plot of the effect of Bailing capsule on proteinuria

anticoagulation, coagulation, and fibrinolysis systems in human body and ending up in hyperlipidemia, ultimately leading to the dysfunction of glomeruli with disordered structure ${ }_{[11]}$. Studies have shown that ${ }_{[12-13]}$ proteinuria can cause damages to glomerular intrinsic cells such as mesangial cells and podocytes as well as to tubulointerstitium. Persistent proteinuria can lead to the progression of renal injury and the level of proteinuria is closely related to the development of chronic renal failure. Therefore, the reduction of proteinuria is an important target for the treatment of $\mathrm{NS}_{[14]}$. The results of this study revealed that Bailing capsule can effectively reduce proteinuria in patients with NS with a mechanism probably related to inhibition of the formation of glomerular sub epithelial immune complex, lowering the loss of anionic charge in glomerular basement membrane and alleviating glomerular high filtration. Furthermore, it has been reported that ${ }_{[15]}$ Bailing capsule can inhibit the activation of aldose reductase, thus reducing the permeability of glomerular basement membrane and reducing urinary protein.

Patients with NS are also characterized by hyperlipidemia. The deposed lipid can stimulate the proliferation of glomerular mesangial cells, increase extracellular matrix synthesis, promote tubulointerstitial fibrosis and glomerular sclerosis and thus aggravate renal injury [16-17]. Additionally, hyperlipidemia will exacerbate the risk of cardiovascular disease, so it is also an independent risk factor for the progression of $\mathrm{NS}_{[18]}$. The 2 studies included in this paper showed that Bailing capsule can reduce total cholesterol, triglyceride and LDL with the mechanism may associated with reduced lipid peroxide as well as enhanced superoxide dismutase and lecithin cholesterol acyl transferase (LCAT) activity.

It was also revealed in this study that Bailing capsule can improve the level of serum albumin in patients, which may be related to proteinuria reduction and that meanwhile Bailing capsule enables to promote protein synthesis with an adrenocorticoid like effect.

However it is necessary to draw attention to the following limitations of the study, such as there was obvious inter-study heterogeneity among the trials, differing in basic treatment program, drug dose and duration of therapy as well as patient's pathological type and clinical manifestations; there was publication bias; there was limited number of studies of low quality and the cited documents all were Chinese version; the longterm efficacy of Bailing capsule failed to be observed.

To sum up, this analysis shows that Bailing capsule can effectively reduce proteinuria and increase plasma albumin and may reduce blood lipids in patients with NS. But these need to be confirmed by further largescale trials of high quality.

\section{Conflict of interest:}

No conflict of interest between any of the authors.

\section{REFERENCES}

1. Musa AM, Asha HA, Veress B. Nephrotic syndrome in Sudanese patients with schistosomiasis mansoni infection. Ann Trop Med Parasitol 2016;74:615-8.

2. Giglio S, Provenzano A, Mazzinghi B, Becherucci F, Giunti $\mathrm{L}$, Sansavini $\mathrm{G}$, et al. Heterogeneous genetic alterations in sporadic nephrotic syndrome associate with resistance to immunosuppression. J Am Soc Nephr 2015;26:230-6.

3. Kengne SW, Massella L, Diomedi FC, Gianviti A, Vivarelli M, Greco M, et al. Risk factors for cyclosporin a nephrotoxicity in children with steroid-dependant nephrotic syndrome. Clin J Amer Soci Nephro 2016;4:1409-16.

4. Gee HY, Zhang F, Ashraf S, Kohl S, Sadowski CE, Vega-Warner V, et al. KANK deficiency leads to podocyte dysfunction and nephrotic syndrome. J Clin Invest 2015;125:2375-84.

5. Kaneko K, Tsuji S, Kimata T, Kitao T, Yamanouchi S, Kato S. Pathogenesis of childhood idiopathic nephrotic syndrome: a paradigm shift from T-cells to podocytes. World J Pediatr 2015;11:21-8.

6. Cheung JK, Li J, Cheung AW, Cheung AW, Zhu Y, Zheng $\mathrm{KY}$, et al. Cordysinocan, a polysaccharide isolated from cultured Cordyceps, activates immune responses in cultured T-lymphocytes and macrophages: signaling cascade and induction of cytokines. J Ethnopharmacol 2009;124:61-8.

7. Zhang JS. Effect of bailing capsule to treat chronic nephritis proteinuria. Chin J Mord Durg Appl 2010;4:30-31.

8. Wang W, Zhang XN, Yin H, Li XB, Hu XP, Liu H, et al. Effects of bailing capsules for renal transplant recipients: a retrospective clinical study. Chin Med J 2013;126:1895-9.

9. Zhang J, Xie S. Meta-analysis of the efficacy of bailing capsules on primary nephrotic syndrome. Chin J Mod Appl Pharm 2013;30:907-10.

10. Zuo L. The impact of prednisone and Bailing capsule on hem rheology of patients with nephrotic syndrome. Chin J Ethnomed Ethnopharm 2009;18:64-5. 
11. Zhong W, Yang LR, Ni N. The combination treatment of fluvastatin and Bailing capsule for primary nephrotic syndrome. Anthol Med 2005;24:671-2.

12. Cao H. Clinical study on therapy of bailing capsule for Nephrotic syndrome. Mod Diagn Treat 2013;24:791.

13. Sha L, Wang L. The clinical observation of corbrin capsule to treated primary nephrotic syndrome. Guide Chin Med 2017;15:26-8.

14. Chen $\mathrm{C}$. The therapeutic effectiveness of atorvastatin and Bailing capsules in the treatment of nephrotic syndrome. J Clin Nephrol 2010;10:281-3.

15. Yadav UC, Ighani-Hosseinabad F, Van Kuijk FJ, Srivastava SK, Ramana KV. Prevention of posterior capsular opacification through aldose reductase inhibition. Invest Ophthalmol Vis Sci 2009;50:752-9.

16. He $\mathrm{L}, \mathrm{Wu} \mathrm{P}, \operatorname{Tan} \mathrm{L}, \mathrm{Le} \mathrm{B}, \mathrm{Du} \mathrm{W}$, Shen $\mathrm{T}$, et al. Characteristics of lipid metabolism including serum Apo lipoprotein $\mathrm{M}$ levels in patients with primary nephrotic syndrome. Lipids Health Dis 2017;16:167.
17. Chang JF, Lin WN, Tsai CC. Resolution of Late SteroidResponsive Nephrotic Syndrome in a Patient with Alport Syndrome Treated with Atorvastatin. Open J Pediatr 2015;5:12-6.

18. Kengne SW, Massella L, Diomedi FC, Gianviti A, Vivarelli $\mathrm{M}$, Greco $\mathrm{M}$, et al. Risk factors for cyclosporin a nephrotoxicity in children with steroid-dependent nephrotic syndrome. Clin J Am Soc Nephrol 2016;4:1409-16.

This is an open access article distributed under the terms of the Creative Commons Attribution-NonCommercial-ShareAlike 3.0 License, which allows others to remix, tweak, and build upon the work noncommercially, as long as the author is credited and the new creations are licensed under the identical terms

This article was originally published in a special issue, "XXXXXX"

Indian J Pharm Sci 2020:82(1)spl issue1; XX-XX 